\title{
PEMERTAHANAN BAHASA IBU MELALUI GRUP WA
}

Mother Languages Maintenance Through Whatsapp Group (Wa)

\author{
Sahril \\ Balai Bahasa Sumatra Utara \\ sahrilmelayu@gmail.com
}

\begin{abstract}
Abstrak
Pemertahanan bahasa dapat terjadi bila suatu komunitas secara kolektif menggunakan bahasa itu sepenuhnya. Penggunaan bahasa ibu yang terjadi pada komunitas di grup WhatsApp Cendekiawan Batubara sangat mendukung upaya mempertahankan eksistensi bahasa ibu dari kepunahan bahasa Melayu dialek Batubara. Kajian ini terfokus pada beberapa kosakata arkais bahasa Melayu dialek Batubara yang tidak lagi dipakai dalam komunikasi etnis Melayu Batubara itu sendiri. Kajian ini berusaha menemukan deskripsi pemertahanan bahasa ibu yang secara tidak langsung telah dilakukan oleh komunitas di grup WhatsApp Cendekiawan Batubara.

Kata Kunci: pemertahanan, bahasa ibu, WA.
\end{abstract}

\begin{abstract}
Language preservation could occur if a community collectively used the language wholly. The use of mother language in communities such as in Cendekiawan Batubara WhatsApp group truly supported the effort to preserve the existence of Melayu Batubara language from extinction. This study focused on some archaic vocabularies in Melayu Batubara language that are no longer used in Melayu Batubara communities themselves. This study aimed to describe the language preservation of mother language which indirectly has been carried out by Cendekiawan Batubara WhatsApp group.

Key words: language preservation, mother language, WhatsApp
\end{abstract}

\section{PENDAHULUAN}

Layanan jejaring social messenger sedang marak belakangan ini. Banyak pengguna mengunduhnya, bahkan menempati posisi atas dalam daftar unduhan terbanyak di toko aplikasi seperti google play. Beberapa layanan jejaring sosial tersebut, antara lain Line, Kakao Talk, WeChat, dan WhatsApp. Keempat layanan messenger tersebut terindikasi sedang populer di mata pengguna internet.

WhatsApp (WA) didirikan oleh pria asal Ukraina, Jan Koum bersama temannya Brian Acton pada tanggal 24 Februari 2009. WA menawarkan keunikan tersendiri, yang mana mekanisme log-in dilakukan melalui nomor ponsel pengguna. Penamaan WhatsApp sendiri diambil dari kalimat "what's up" yang biasa dipakai untuk 
menanyakan kabar. Perkembangan selanjutnya, pada tanggal 22 Januari 2015, WA telah meluncurkan fitur resmi bernama WhatsApp Web. Melalui fitur ini, pengguna sudah bisa menggunakannya berbasis komputer.

WA adalah aplikasi pesan instan paling populer, sampai September 2015 pengguna WA sudah 900 juta orang secara aktif menggunakannya. WA adalah aplikasi pesan instan untuk smartphone jika dari fungsinya hampir sama dengan aplikasi SMS yang biasa kita gunakan di telepon selular lama. Akan tetapi WA, tidak menggunakan pulsa, melainkan data internet. Jadi, aplikasi ini tidak perlu dikhawatirkan soal panjang pendeknya karakter.

Menurut Kompas.com, yang memuat pernyataan Brian Acton salah seorang pendiri WA, Indonesia masuk dalam lima besar wilayah yang pertumbuhan pengguna WA paling tinggi. Tingginya angka pengguna WA di Indonesia, menurut juru bicara Neeraj Arora, adalah karena penduduknya sering berkomunikasi dibandingkan dengan penduduk negara lain.

Maraknya pengguna WA di Indonesia dikarenakan pengguna bisa mengirim pesan teks, pesan suara, pranala, dan gambar pada pengguna yang lainnya. Di sisi lain aplikasi ini sering menggunakan sebuah peralatan yang mengizinkan pengguna untuk membuat dan mengelola grup yang ada. Semua pengguna bisa masuk ke dalam grup mana saja selama mereka diundang oleh pembuat grup. Selain itu, mereka bisa meninggalkan grup tersebut sesuka mereka.

\section{LANDASAN TEORI}

Menurut Sedyawati (1996), fungsi bahasa ibu/daerah menjadi alternatif berkomunikasi yang ekspresif sesuai dengan naluri dan batin, sehingga bisa memenuhi kebutuhan kultural kita. Dengan berbahasa ibu/daerah dengan orang sedaerah akan bisa mengendurkan saraf-saraf batin dari tekanan-tekanan hidup publik dan tuntutan globalisasi. Tanpa bahasa daerah, kita kekurangan "tempat berteduh" di tengah-tengah kehidupan publik yang sering melelahkan batin kita.

Hal ini sejalan dengan pandangan Lauder (2007), "sebanyak 85 persen penduduk Indonesia masih menggunakan bahasa daerah sebagai bahasa sehari-hari di rumah. Bahasa ibu itu adalah jendela untuk melihat realitas dunia yang sangat kompleks dan sebagai pembentuk perilaku serta jati diri. Bahasa ibu itu juga menjadi jembatan untuk memahami ekspresi nilai, norma, aturan, adat kebiasaan, dan kearifan lokal menjaga lingkungan. 
Dalam tulisan ini penulis mencoba melihat pada grup WA Cendikiawan Batubara. Grup ini dibuat oleh Bang Jamil. Ada dua orang yang menjadi admin grup, yaitu Bang Jamil (Medan) dan Usman Jakfar (Malaysia). Grup WA ini dikhususkan bagi orang-orang yang berasal dari Kabupaten Batubara yang ada di Provinsi Sumatra Utara. Masyarakat Kabupaten Batubara umumnya beretnis Melayu sehingga bahasa yang digunakan dalam grup ini adalah bahasa Melayu dialek Batubara. Hal ini sudah menjadi komitmen bagi anggota grup ini, dengan menggunakan bahasa Melayu dialek Batubara. Hal ini dikarenakan ada kerinduan bagi anggota grup untuk berkomunikasi dalam bahasa ibu mereka. Ini dapat dimaklumi karena mereka berdomisili sudah di luar komunitas masyarakat Melayu Batubara.

\section{METODE PENELITIAN}

Penelitian ini merupakan penelitian deskriptif sinkronis untuk melihat perilaku berbahasa ibu pada grup WA dan menjelaskan fenomena tersebut dari tinjauan ilmu terkait secara deskriptif, sebagaimana adanya di lapangan.

Tujuan dalam penulisan ini adalah mendeskripsikan ciri-ciri bahasa ibu dalam grup WhatsApp, serta melihat implementasi penggunaannya. Kajian ini dilakukan dengan analisis pustaka dan observasi terhadap penggunaan bahasa ibu dalam grup WA. Implementasi penggunaan bahasa ibu dalam grup WA dilihat secara acak dalam beberapa percakapan antara pengguna WA di grup Cendekiawan Batubara.

\section{PEMBAHASAN}

\section{Komunitas Etnik}

Sejalan dengan topik makalah ini, melalui grup WA-lah lahirnya grup-grup yang bersifat komunitas tertentu, seperti komunitas etnik tertentu. Ada komunitas etnik Jawa, Sunda, Batak, dan Melayu. Di dalam komunitas ini terjadi komunikasi melalui pesan dengan menggunakan bahasa ibu atau bahasa daerah masing-masing. Salah satunya adalah grup WA Cendikiawan Batubara yang menggunakan bahasa Melayu dialek Batubara dalam berkomunikasi sesama anggota grup ini.

Sesuatu yang menarik dari komunikasi tersebut adalah tanpa ada rasa sungkan dan malu dalam hal berkomunikasi. Hal ini disebabkan di dalam grup tersebut sudah saling mengenal, sehingga bahasa yang dipakai terkadang sedikit nyeleneh. Begitu juga dengan foto-foto yang dikirim, umumnya untuk hal-hal yang lucu-lucuan saja. 
Sampai saat ini, grup WA Cendekiawan Batubara sudah beranggotakan sebanyak 256 orang termasuk penulis sendiri. Ada 34 anggota yang aktif setiap hari berkomunikasi melalui grup ini. Sesuatu yang menarik dari grup ini adalah anggotanya sekitar 95\% tinggal di luar Kabupaten Batubara yang terbanyak berdomisili di Malaysia. Umumnya, para anggota grup WA ini bergerak dalam bidang pendidikan, yaitu sebagai guru di lembaga-lembaga agama Islam. Mereka tamatan dari universitas-universitas di negara Arab, seperti Mesir, Sudan, Yaman, dan Libya. Bang Jamil sebagai pembuat grup adalah tamatan dari Universitas Al Azhar Mesir, sekarang tinggal di Medan sebagai dosen di Universitas Islam Negeri Sumatra Utara (UINSU). Oleh sebab itulah, mengapa grup WA ini menamakan dirinya Cendikiawan Batubara. Satu hal lagi, semua anggota grup ini adalah kaum laki-laki.

Ahli bahasa akan merasa puas tatkala menganalisis bahasa sebagai suatu sistem, fungsi variabel linguistik tergantung pada gejala-gejala lingustik lain sehingga tidak perlu mencari penjelasan yang berada di luar bahasa untuk menyelesaikan masalah kebahasaan (Mbete, 2010). Dengan demikian, bahasa digunakan oleh manusia yang menjadi anggota masyarakat tertentu memiliki kebudayaan yang khas. Ada kecenderungan bahwa para individu berbeda-beda dalam penggunaan bahasa. Oleh karena itu, variabel sosial, seperti status penutur mempengaruhi cara menggunakan bahasa. Selain itu, orang memilih menggunakan kata-kata agar dapat menyampaikan sesuatu yang berarti. sesuatu yang berarti dalam kebudayaan yang satu dapat berbeda dengan kebudayaan yang lain. Dalam kenyataan, cara menggunakan bahasa mempengaruhi dan dipengaruhi oleh kebudayaan.

Fenomena yang terjadi saat ini, bahwa keberadaan bahasa ibu sangat mengkhawatirkan. Sebagai akibat dari intervensi bahasa Indonesia di wilayah Batubara, bahasa ibu semakin tersudut berdasarkan sudut pandang linguistik dan budaya, hal ini sangat mengecewakan. Padahal, bahasa ibu (daerah) adalah salah satu warisan sejati yang dapat diturunkan kepada generasi penerus sebuah suku bangsa. Tidak dipungkiri bahwa terjadinya perkawinan antaretnis juga secara perlahan membuat tersisihnya bahasa daerah di antara generasi yang ada saat ini (Clark, 2003).

Bahasa ibu saat ini mempunyai pesaing, yaitu bahasa Indonesia dan bahasa Inggris (asing), serta bahasa "gaul".

Keberadaan bahasa Melayu dialek Batubara di Sumatra Utara saat ini berada pada skala tiga, yaitu (1) mulai terancam, (2) mulai dilanda krisis ketahanan secara perlahan, dan (3) mengalami degradasi frekuensi dan kualitas pemakaian. 
Menurut Trask (1997:126), mengungkapkan pemertahanan bahasa merupakan penggunaan sebuah bahasa secara kontinu oleh penuturnya, khususnya dalam keadaan bahasa itu berada dalam tekanan bahasa lain. Hal ini terjadi karena komunitas secara bersama-sama memutuskan untuk terus menggunakan bahasa (atau bahasa-bahasa) yang secara tradisi telah mereka pergunakan.

Bertitik tolak dari uraian tersebut, pemertahanan bahasa ibu dalam penelitian ini dikonsepkan sebagai upaya-upaya yang dilakukan masyarakat agar bahasa ibu Melayu dialek Batubara tetap digunakan. Berkaitan dengan hal itu, loyalitas masyarakat pendukungnya merupakan salah satu faktor penting dalam pemertahanan bahasa ibu. Loyalitas itu berakar pada asal-usul seseorang. Implementasinya terlihat pada tingkah laku seperti tidak malu menggunakan bahasa ibu dalam pergaulan; ikut memperjuangkan bahasa ibu secara resmi; ikut mengoreksi kesalahan bentuk bahasa ibu yang dipakai orang lain.

\section{Bahasa Ibu di WA}

Istilah bahasa pertama 'first language' digunakan berbeda-beda. Menurut Bloomfield (1973), bahasa yang pertama dipelajari seseorang dalam berbicara adalah bahasa aslinya (native language). Dalam hal ini, dia adalah penutur asli (native speaker) dari bahasa itu. Dijelaskan bahwa native language adalah istilah yang digunakan untuk bahasa yang pertama yang dipelajari anak. Istilah ini juga dikenal sebagai bahasa utama (primary language), bahasa ibu (mother tongue), dan bahasa pertama (first language).

Berdasarkan fungsinya, bahasa pertama juga digunaan untuk mengacu pada bahasa yang paling banyak atau sering digunakan seseorang. Istilah bahasa pertama juga digunakan untuk merujuk pada tingkat penguasaan sesorang terhadap bahasa. Istilah bahasa ibu (mother tongue atau mother language) digunakan juga untuk bahasa yang dipelajari seseorang di rumah (terutama dari orangtua mereka). Berdasarkan definisi ini, anak-anak yang dibesarkan dalam keluarga yang dwibahasa (bilingual) memiliki lebih dari satu bahasa ibu (Kridalaksana: 1993).

Sesuatu yang menarik dari grup WA Cendekiawan Batubara ini adalah penggunaan bahasa ibunya. Walaupun anggota grup ini sudah tidak lagi tinggal di wilayah Batubara, bahkan sudah banyak pula yang tinggal di luar negeri, seperti Malaysia, Brunai Darussalam, bahkan ada yang di Yaman. Mereka tetap menggunakan bahasa ibu (bahasa Melayu dialek Batubara) dalam setiap komunikasinya. Menurut Bang Jamil, sebagai 
pembuat grup WA Cendekiawan Batubara ini menekankan bahwa anggotanya harus berkomunikasi dengan menggunakan bahasa Melayu dialek Batubara.

Bahasa Melayu dialek Batubara yang mereka gunakan pun cukup kental, yaitu kosakata arkais yang tidak dimengreti anak-anak muda berdomisli di wilayah Batubara.

Misalnya, dialog antara Safri M. Zein (Malaysia) dan Rasyid Ahmad (Medan) pada Sabtu, 12 Maret 2016.

\begin{tabular}{|c|c|}
\hline Safri & sodap tu... uda lamo tak makan gulai ayam. \\
\hline Rasyid Ahmad & $\begin{array}{l}\text { Safri... co kau leteh Suhaimi tu. Kain busuk dio campakan } \\
\text { ke palimbahan. }\end{array}$ \\
\hline Edi (Riau) & $\begin{array}{l}\text { Udalah mat kasian kabapaan odan tu, jgn kau lete dio lg. } \\
\text { Lalu masuklah }\end{array}$ \\
\hline Suhaimi (Medan) & $\begin{array}{l}\text { :...ondak cangking palo kau....awas macam2 odan tangkap } \\
\text { masuk kan ke dalam lukah. }\end{array}$ \\
\hline Edi & $\begin{array}{l}\text { : ciri khas bakombuh di grup ini, patamo2 motan, terakhir } \\
\text { menjelenge..... }\end{array}$ \\
\hline
\end{tabular}

Melalui dialog dalam komunikasi antara anggota grup WA Cendekiawan Batubara ini terlihat penggunaan bahasa ibu yang cukup kental. Beberapa kosakata memang sama dengan bahasa Indonesia, hanya berbeda dari segi dialek. Akan tetapi, ada juga beberapa kosakata yang tidak ditemukan dalam bahasa Indonesia walaupun dari segi permainan dialeknya. Misalnya: co 'coba', leteh 'marahi', kabapaan 'paman', odan 'saya; aku', cangking 'pukul', lukah 'bubu', bakombuh 'berbicara', motan 'serius', menjelenge 'bercanda'.

Selanjutnya, selama mengikuti grup WA Cendekiawan Batubara ini, penulis menemukan beberapa kosakata yang cukup arkais, yang orang-orang di wilayah Batubara sendiri pun sudah jarang menggunakannnya dalam berkomunikasi. Beberapa kosakata tersebut, di antaranya: bagulung 'berselimut', ontok 'tempat tinggal; alamat', basalubung 'menutup seluruh tubuh dengan kain sarung', bacongkang 'berkelahi dengan adu mulut; dengan adu kata-kata', lonjo 'letih akibat dikerjakan oleh teman-teman sendiri', judu 'judes; tidak mau kalah jika dalam berdebat', koso 'tidak mau', hajap 'capek', hontam 'membiarkan', layang kepetek 'sejenis nama layang-layang', manjelejeh 'menetes', salemo 'ingus', dan mancaut 'memaki; berkata-kata tidak senonoh'.

Berikut ini beberapa kosakata bahasa ibu Melayu dialek Batubara yang sudah jarang digunakan dalam kehidupan sehari-hari di wilayah Batubara, tetapi muncul dari dialog-dialog pada grup WA Cendekiawan Batubara.

(1) badongking 'keras sekali untuk kayu' 
(2) balasah 'dikerjain', odan kono balasah bek budak2 ne 'aku dikerjain oleh anak-anak ini

(3) bek 'oleh'

(4) bongak 'bohong/dusta'

(5) bonto 'sejenis rumput ilalang'

(6) boyan 'sebuatan untuk orang sepengambilan; dua orang laki-laki menikahi dua orang perempuan yang bersaudara kandung, maka panggilan untuk sesama suami itu adalah boyan.

(7) mampalutukan 'menuduh', uang sayang... selalu mempalutukannyo 'orang sayang ..... selalu menuduhnya'

(8) mandongkung 'memukul dari belakang'

(9) mencolah 'menimpali' itu kombu para tuan guru, sogan ati nak mencolah 'itu cerita para tuan guru, segan hati hendak menimpali'

(10) mengoko 'tertawa terbahak-bahak', pura2 membela kau, tapi mengoko golak dio 'pura-pura membela, tetapi tertawa terbahak-bahak'

(11) nginjam 'merasai'

(12) odan ne 'saya ini', babunyi hp odan ne 'berbunyi hp aku'

(13) pojo kaolah 'amit-amit'

(14) tacogut 'kelolotan karena banyak minum air'

(15) takalucut 'melorot', kalau pakai celana bosa bono takalucut dio 'kalau pakai celana yang besar melorot dia'

(16) takalujut 'kelolotan; lemas; tersedak'

(17) tuja 'pukul', tuja ajo dio 'pukul saja dia'

Ciri khas bahasa Melayu dialek Batubara ini, yaitu selalu menggunakan vokal /o/ pada akhir kata, jika kata tersebut berakhir dengan vokal /a/, misalnya: dia dio, kemana kemano, apa apo. Ada juga huruf /a/ pada posisi kedua dalam kata berubah menjadi huruf /o/, misalnya: pasar posa, pantang pontang. Huruf /r/ umumnya hilang pada awal, tengah, dan akhir kata, misalnya: rumah $\sim$ umah, orang $\sim$ ohang/uang, cakar caka. Vokal /e/ pada posisi kedua dalam kata tersebut berubah menjadi vokal /o/, misalnya pelit polit, lemas lomas. Awalan /ber/ berubah menjadi awalan /ba/, misalnya: berbunyi $\sim$ babunyi, bersilat $\sim$ basilat, berbini $\sim$ babini. Awalan $/ \mathrm{me} /$ berubah menjadi awalan /ma/, misalnya menjadi $\sim$ manjadi, menjala $\sim$ manjalo, menolak $\sim$ manulak. Awalan /ter/ berubah menjadi awalan /ta/, misalnya terbit tobit, termakan $\sim$ tamakan.

Selebihnya hanya bersifat perubahan bunyi dari kosakata bahasa Melayu lainnya atau kosakata bahasa Indonesia, misalnya kecil $\sim$ kocik, peluh $\sim$ poluh, obat $\sim$ ubat, coba $\sim$ cubo, dan giliran $\sim$ gelean.

Ditemukan juga beberapa kata kalau dalam bahasa Indonesia terasa kasar dan bukan untuk manusia, tetapi dalam bahasa Melayu dialek Batubara justru tidak kasar, misalnya untuk kata perempuan atau wanita disebut 'batino' betina, anak-anak 'budak', hamil 'bunting; buncit', saudara tiri sodaho anjing. 


\section{Pemertahanan dari ketirisan diglosia}

Secara teoretis dampak kepunahan bahasa daerah/ibu di Indonesia, yang kecenderungannya sudah mulai tampak pada pergeseran bahasa daerah itu, baik yang minor maupun yang mayor. Kecenderungan ini tampak pada gejala ketirisan diglosia bahasa Indonesia-bahasa daerah dan pada gejala ketirisan dinomia yang melibatkan budaya nasional dan budaya daerah. Misalnya, pada nosi makrofungsi bahasa menurut Garvin dan Mathiot (1968), yakni bahasa sebagai (1) pemersatu (unifying) dan (2) pemisah (separatist). Dari sini beberapa implikasi coba ditarik: (1) budaya daerah (secara teoretis) akan ikut punah bersama punahnya bahasa daerah; (2) kemungkinan timbulnya provinsialisme (dan implikasinya timbulnya gerakan separatisme) menjadi berkurang; (3) biaya pemeliharaan bahasa daerah dapat ditiadakan dan biaya pemelajaran bahasa nasional dapat dikonsentrasikan pada perencanaan dan pemelajaran bahasa Indonesia agar bahasa ini mencapai taraf modern dan efektif; (4) segala upaya dapat dikonsentrasikan untuk melawan dominasi bahasa Inggris terhadap bahasa nasional; (5) rasa kebangsaan rakyat Indonesia akan cenderung menjadi lebih kuat; (6) keragaman budaya menjadi berkurang. Pergeseran bahasa daerah itu bertolak dari anggapan dasar bahwa ada persaingan antara bahasa daerah dan bahasa Indonesia, yang nama geopolitis dari bahasa Melayu.

Fase-fase yang ditempuh oleh bahasa Melayu menjadi bahasa kedua setempat kiranya dapat dianalogikan dengan postulat Moag (1982). Mula-mula bahasa Melayu ditransportasi ke daerah-daerah di nusantara ini, yakni ke daerah-daerah yang sebelumnya tidak menggunakan bahasa Melayu. Kemudian bahasa Melayu mengalami indigenisasi, seperti yang dapat diinferensikan dari adanya bahasa Melayu Manado dan Melayu Ambon. Bahasa Melayu mengalami fase ekspansi ketika tidak hanya digunakan di ranah niaga, melainkan di ranah yang lain, seperti ranah agama dan pendidikan. Fase puncak yang dialami oleh bahasa Melayu adalah institusionalisasi ketika putra-putri daerah mulai menulis roman-roman di dalam bahasa Melayu. Ketika itulah benih-benih "persaingan" di antara bahasa Melayu dan bahasa daerah dapat diasumsikan mulai tumbuh. Lambat tetapi pasti, bahasa Melayu mulai tumbuh menjadi bahasa primer dan bahasa daerah berubah fungsi menjadi bahasa sekunder. Persaingan linguistik itu menjadi lebih keras ketika bahasa Melayu diberi nama geopolitis bahasa Indonesia dan ditetapkan sebagai bahasa negara. Konsekuensinya adalah bahwa bahasa pengantar pendidikan adalah bahasa Indonesia. Bahasa Indonesia menjadi lebih dominan dibandingkan bahasa daerah/ibu (salim, 2002). 
Berdasarkan teori Mackey (1973) tentang geolinguistik bahasa, tampak bahwa bahasa daerah/ibu kalah bersaing dengan bahasa Indonesia. Dewasa ini ada fenomena yang menunjukkan bahwa bahasa daerah/ibu terdesak oleh bahasa Indonesia dan mulai tergeser. Bagi banyak orang Indonesia, bahasa Indonesia telah benar-benar menjadi bahasa primer dan tidak sedikit keluarga yang sudah menggunakannya sebagai bahasa pertama, menggeser bahasa daerah/ibu. Dahulu bahasa Indonesia dan bahasa daerah hidup berdampingan "secara damai". Pilihan atas bahasa Indonesia atau bahasa daerah hanya berdasarkan keperluan semata-mata. Secara umum, untuk komunikasi intrakelompok dipilih bahasa daerah dan untuk komunikasi antarkelompok dipilih bahasa Indonesia. Kemudian, masyarakat mempunyai preferensi: untuk hal-hal yang diasosiasikan dengan hal-hal yang tinggi dipilih bahasa Indonesia dan untuk hal-hal yang dianggap tidak tinggi dipakai bahasa daerah. Di dalam sosiologi bahasa situasi kebahasaan yang di dalamnya ada pembagian fungsi seperti ini disebut diglosia. Adanya diglosia tidak otomatis mengancam bahasa daerah. Selama pembagian tugas itu dipraktikkan secara taat asas-selama ada kompartmentalisasi antara bahasa Indonesia dan bahasa daerah - kelangsungan hidup bahasa daerah/ibu aman-aman saja.

Menurut Kridalakasana (1993: 22-23), bahasa pertama yang dikuasai manusia sejak awal hidupnya melalui interaksi dengan sesama anggota masyarakat bahasanya atau yang sering disebut dengan konsep bahasa ibu (native language atau mother language) diperoleh secara intuitif. Dengan demikian, dalam pemerolehan kebudayaan setempat oleh seorang anak manusia yang menjadi anggota masyarakat di tempat itu berlangsung pula secara intuitif dan simultan tatkala mereka mempelajari bahasa ibunya. Melalui galur-galur ungkapan yang mapan, sistem gramatika dan leksikon yang tersedia dalam bahasa ibu, seorang anak manusia yang menjadi anggota masyarakat telah dibentuk cara pandang nilai-nilai yang berlaku dalam masyarakat bahasa dan budaya setempat.

\section{SIMPULAN}

Kekhawatiran pemerintah akan punahnya bahasa ibu, sebenarnya sudah diantisipasi, yaitu dengan dikeluarkannya Peraturan Menteri Dalam Negeri Nomor 40 Tahun 2007 tentang Pedoman bagi Kepala Daerah dalam Pelestarian dan Pengembangan Bahasa Negara dan Bahasa Daerah. Kiranya peraturan ini harus dijadikan acuan dalam penanganan bahasa daerah serta dijabarkan ke dalam peraturanperaturan daerah di setiap provinsi untuk mendukung upaya pemeliharaan, pelestarian, 
dan pengembangan bahasa daerah. Kekhawatiran secara global pun sudah terjawab juga melalui Badan PBB yang membidangi pendidikan, ilmu pengetahuan dan kebudayaan Unesco yang telah mencanangkan tanggal 21 Februari setiap tahunnya diperingati sebagai hari bahasa ibu internasional.

Mengingat urgensi peran bahasa ibu, sebagai sarana komunikasi internal, medium pembangunan, pengembangan, dan pewarisan budaya pada setiap anggota komunitasnya perlu dilestarikan agar dapat mempertahankan bahasa ibu. Untuk usia kelas permulaan pada tingkat pendidikan dasar kelas 1-3 sekolah dasar (SD) / madrasah ibtidaiah (MI) sebagai usia masih subur dalam pemerolehan bahasa (termasuk bahasa ibu), sebaiknya penggunaan bahasa pengantar dalam pendidikan pada jenjang tersebut menggunakan bahasa ibu.

\section{DAFTAR PUSTAKA}

Bloomfield, L. 1973. Language. London: COX Wyman Ltd.

Clark, Eve V. 2003. First language acquisition. Cambridge: Cambridge University Press.

Garvin, P.L. dan Madeleine Mathiot.1968. The Urbanization of the Guarani Language; A Problem in Language and Culture. Dalam Fishman (Ed) Reading in the Sociology of Language. Mouton: Paris.

Kridalaksana, Harimurti. 1993. Pembentukan Kata dalam Bahasa Indonesia. Jakarta: Gramedia Pustaka Umum.

Mackey, I.R.A. 1973. Phonological primitives: Electromyographic speech error evidence. Canada: University of Ottawa.

Mbete, Aron Meko. 2010. Problematika Keetnikan dan Kebahasaan dalam Perspektif Ekolinguistik. Sebuah Refleksi Ringan (artikel).

Moag, R.F. 1982. The Other Tongue. New York: Prentice Hall.

Salim. 2002. Perubahan Sosial Sketsa Teori dan Refleksi Metodologi Kasus Indonesia. http://wikipedia.org/perubahan_sosial/ (Diunduh, 6 Maret 2016).

Trask, Robert Lawrence .1997. Language: The Basics (ed. 2nd). Psychology Press. 